\title{
ANTONIO NÚÑEZ DE MIRANDA, CONFESOR DE SOR JUANA: UN ADMINISTRADOR POCO COMÚN
}

\author{
María Águeda MÉNDEZ \\ El Colegio de México
}

Para María Dolores BRAVO

En varias ocasiones se han descrito las labores del jesuita Antonio Núñez de Miranda: persona muy respetada, de gran influencia y autoridad moral, ávido lector de memoria privilegiada, confesor de personas influyentes, virreyes y de monjas (entre ellos el marqués de la Laguna y sor Juana Inés de la Cruz), durante unos meses provincial de la Compañía de Jesús (Robles 1972, pp. 275 y 287), por treinta y dos años prefecto de la Congregación de la Purísima Concepción de la Virgen María', calificador del Tribunal del Santo Oficio novohispano durante treinta y cuatro (Méndez 1997, p. 400), y, por si lo anterior fuera poco, prolífico y fino escritor de textos en su mayoría dogmáticos y normativos ${ }^{2}$ (cfr., Beristáin y

I Hay una discrepancia en cuanto a los años en que el padre Núñez ocupó tal cargo en la Congregación. Según Robles «más de treinta y cinco años gastó en servicio de la Congregación de la Purísima» (1947, t. 3, p. 12); según Oviedo (1702, p. 203), fueron treinta y dos. Núñez sustituyó al fundador y prefecto superior Juan Castini que murió en septiembre de 1663 y se ocupó de llevar las riendas de la Congregación hasta su muerte en 1695, por lo que, efectivamente, fue prefecto durante treinta y dos años (Archivo General de la Nación de México [en adelante AGN], Temporalidades, vol. 229 fols. 18v-19r).

2 Sobre algunos de los muchos escritos del padre Núñez, véanse —además del artículo incluido en esta revista - la importante recopilación de estudios de María Dolores Bravo Arriaga (1997), en especial: «Erotismo y represión en un texto del padre Antonio Núñez de Miranda», pp. 4954, «La retórica de la conciencia: Cartilla de la doctrina religiosa del padre Antonio Núñez de Miranda», pp. 55-62, «Dos dedicatorias de Núñez de Miranda a sor Filotea de la Cruz, indicios inéditos de una relación peligrosa», pp. 63-71 y «La excepción y la regla: una monja según el discurso oficial y según sor Juana», pp. 73-82. 
Souza 1883 , t. 4, pp. 31-33, Decorme 1941, t. 1, passim, Oviedo 1702, passim y Zambrano 1970, t. 10, pp. 513-557).

Parecería que sus múltiples labores serían más que suficientes, pues pasó gran parte de su vida estudiando, escribiendo, calificando escritos y hechos, impartiendo su acreditada palabra y bendiciones, e influyendo de manera decisiva en la vida de muchos, ya religiosos, ya ricos o poderosos, ya seres de poca monta. Sin embargo, la Compañía de Jesús a veces le encomendó - y otras le permitióocuparse de algo que a primera vista parecería tener poco que ver con su importante prestancia, prestigio y variadas ocupaciones: por ser depositario de la capellanía del capitán Juan de Chavarría Valera, se encargó de la administración de una hacienda en Acolman ${ }^{3}$, en 1683.

Sabido es que las distintas órdenes religiosas vivían de sus rentas; era común que los eclesiásticos prestaran dinero a rédito o hicieran inversiones para conseguir fondos que financiaran el desarrollo de la orden ${ }^{4}$. Los jesuitas, además, participaban en la vida económica de manera activa; era frecuente que invirtieran en haciendas y tierras, compraran y vendieran en el mercado y que administraran sus propiedades, muchas de las cuales les venían de diezmos, donaciones destinadas a obras pías, hipotecas o capellanías (cfr., Riley 1976, pp. 5-6), ya que «devotos terratenientes gravaban sus propiedades para hacer donaciones destinadas a obras pías o bien contribuían con dinero a varias organizaciones que pertenecían a la Iglesia» (ibid., p. 13).

Es lícito preguntarse la razón por la cual el padre Núñez tendría que hacerse cargo de actividades como éstas, pues las que normalmente le ocupaban tendrían que consumir gran parte de su tiempo y, sobre todo, por ser de índole muy distinta, mantenerle alejado de ellas. Es preciso recordar que algo que mucho preocupaba a la Compañía era que sus intereses fueran bien manejados $y$, más que nada, por hermanos confiables y honestos, pues en ello residía gran parte del posible éxito de sus empresas: preferían personas de confianza más que profesionales capacitados y hábiles en el manejo de sus finanzas (cfr., Riley 1976, pp. 57-

Si bien en un principio perteneció a la jurisdicción de San Juan Teotihuacán, hacia fines del XVII quedó sujeta a la de Tezcoco (Gerhard 1986, p. 282). Es una región dividida hoy entre los estados de México y Tlaxcala. En el siglo XVI Acolman fue encomendada a Pedro Núñez y en 1528 reasignada a Pedro de Solís Barrasa, conquistador, a quien sucedió un hijo, Francisco de Solís Orduña (ca. 1565) y un nieto, Francisco de Solís y Barrasa, hacia 1610 (ibid., p. 321).

4 Sirva de ejemplo sor Juana, que por ser contadora del convento de San Jerónimo y en colaboración con Mateo Ortiz de Torres, mayordomo del mismo, además de llevar minuciosamente las cuentas, se dedicaba a tales transacciones (cfr., Trabulse 1996, pp. 18-19). 
58). Es muy probable que en ello radique el porqué de la participación del conocido e influyente jesuita.

Hay que tomar en cuenta, además, que el padre Núñez no era ningún neófito en tales menesteres, ya que había tenido que ver con testamentarías y capellanías en otros momentos de su vida. Tal es el caso de las que habían mandado instituir el médico Diego de Herrera en 1677, nombrando como albaceas al abogado de la Real Audiencia, Juan de Valdés y al propio jesuita con dote de dos mil pesos (AGN, Bienes nacionales, vol. 1442, exp. 12), la del capitán Andrés de Carvajal y Tapia de $1678^{5}$ (Oviedo 1702, p. 117 y Decorme 1941, t. 1, pp. 316-317), la de Carlos de Santa Rosa, antes Bartolomé de Guevara Lorite, congregante de la Purísima, de 1680 (Robles 1972, t. 1, p. 274) o la del licenciado Diego Verdugo (AGN, Bienes nacionales, vol. 538, exp. 3 ).

En los textos sobre el padre Núñez se hace poca mención de esta importante labor del jesuita hacia la Compañía. En la obra fundamental sobre su vida (Oviedo, 1702) hemos localizado cuatro consignas, las cuales no desdoran - ni mucho menos- la intención hagio-biográfica del escrito dieciochesco, ya que sirven para ensalzar la figura del padre. Es importante anotar que todas se refieren al capitán Juan de Chavarría ${ }^{6}$.

Cabe preguntarse, entonces, quién era este personaje. Hasta el momento sólo contamos con datos aislados de fuentes indirectas. Éstas no nos proporcionan más que información sobre algunos hechos en su vida que han sido consignados, lo cual indica la importancia del capitán, ya por sus méritos propios, ya por su —para la época-inmenso caudal ${ }^{7}$, ya por sus obras. Como veremos más adelan-

5 En realidad, la obra pía de Carvajal y Tapia fue legada a la Congregación de la Purísima. Ésta «ađmitió [...] ser la administradora» desde 1678. Evidentemente, siendo el padre Núñez el prefecto superior, mucho debe de haber tenido que ver con la distribución de la misma: «el hospital más favorecido fue 'los pobres inocentes' es decir, de los dementes del hospital de S. Hipólito; viendo el P. Núñez lo que padecían, les procuró una renta de 15.000 pesos para la cena diaria [...]». También el capitán Chavarría asistió al hospital, pues por conducto del padre Núñez se les procuraron tres mil pesos para el desayuno «que ofreció liberalmente el capitán [...]». (Decorme 1941, t. 1, p. 537).

6 El apellido del capitán sufre modificaciones según el tex to de que se trate. Hay veces que se le denomina Juan de Chávarri, otras Juan de Echeverría (Echavarría, Echabarría, Echeverría o Echeberría). La mayor parte de las veces, así como en el sermón del padre Núñez, se le consigna como Juan de Chavarría que es el que hemos preferido aquí. No está de más anotar la posible confusión con un homónimo, sargento mayor, que murió ocho años antes que nuestro personaje (Robles 1972, t. 1, p. 153).

7 Buena fortuna debería de ser, pues dio para muchas edificaciones. Aunada a los dineros de Carvajal y Tapia, «caudales que sin reserva pusieron» en manos de Núñez, éste pudo mandar levantar «la hermosa capilla de la Purísima Concepción en el Colegio de S. Pedro y S. Pablo de México, la iglesia del colegio de S. Gregorio, el colegio de S. Andrés, el templo de S. Lorenzo y gran parte del monasterio de Balvanera [...]». (Beristáin de Souza 1883, t. 4, p. 31). 
te, el padre Núñez, si bien conoció al capitán muy de cerca, nada más dejó —que sepamos - un sermón laudatorio sobre él. Desgraciadamente, ninguno de estos escritos nos proporciona los elementos necesarios para ubicar a Chavarría de lleno en su tiempo ${ }^{8}$.

En orden cronológico, la primera noticia que tenemos es del 16 de junio de 1650 en que salió una solemne procesión de la Catedral hacia la iglesia de San Lorenzo, con motivo de su dedicación. Ya en ella, tomaron sus asientos los asistentes principales y al capitán Chavarría, «patrón de dicha iglesia», se le sentó -en lugar importante-, al lado del corregidor más antiguo (Guijo 1986, t. 1, p. 112). El 26 de diciembre de 1652 recibió el hábito de caballero de la Orden de Santiago en la misma iglesia y el primero de enero de 1653 fue electo alcalde ordinario 9 (ibid., pp. 204-205). En 1661, el nuevo virrey conde de Baños volvió a formar un batallón que años antes se había levantado. Los entonces capitanes tendieron banderas, largaron sus capas y reunieron a sus soldados, so pena que de no hacerlo tendrían que pagar multas que oscilaban entre dos mil y cinco mil pesos. El capitán Juan de Chavarría, entre otros, «con gran gala» recibió de nuevo la bandera en su casa el 24 de julio y fue ratificado (ibid., pp. 155-156). En 1664 hospedó en su casa al obispo de Puebla y virrey Diego Osorio de Escobar y Llamas «por dar lugar a que se aliñase el arzobispal para la venida del señor arzobispo» [doctor Alonso de Cuevas Dávalos]. (Ibid., p. 237).

El 15 de febrero de 1675 se dio vara de alcalde ordinario al conde Santiago y la antiguiedad a nuestro capitán (Robles 1972, t. 1, p. 163). No podían faltar las malas noticias: el 25 de junio de 1676 murió su hija (ibid., p. 198). Tampoco podía faltar — dado el tenor del Diario de Robles- un dato, por demás curioso, de agosto de 1679: «dicen parió una mula en la hacienda de D. Juan de Chavarría y que sucedió otro caso semejante en Parral» (ibid., p. 198).

8 En su sermón (Núñez 1684, fols. 10v-11r) el jesuita incluye muy de pasada: «[...] los puestos públicos que ocupó nuestro difunto cavallero, assí políticos, desde el Consular de alcalde ordinario, como militares de capitán, etcétera, en esta Imperial Corte y República Mexicana, madre dichosa suya», parca descripción que nada añade. Por otra parte, con excepción de Guijo (1986) y Robles (1947), los textos de Oviedo (1702) y Zambrano (1970), ambos jesuitas, mencionan al acaudalado capitán sólo en relación con el padre Núñez. La intención del primero es glorificar y encumbrar a su correligionario; la del segundo, dejar asentados los hechos y escritos del destacado miembro de la Compañía.

9 Robles, por su parte, informa que el 1 de enero de 1675 salieron por alcaldes ordinarios el conde de Santiago «que no tomó luego la vara por estar legítimamente [sic] impedido» y don Juan de Chavarría (1972, t. 1, p. 157). 
En 1681, a instancias del padre Núñez, Chavarría sufragó los gastos que ocasionó la reedificación de la iglesia de San Gregorio ${ }^{10}$ para el culto del santo, accedió a ceder la hacienda de Acolman y que fuera destinada a la educación de los indios (Decorme 1941, t. 1, p. 93). Este hecho es aprovechado por Oviedo para elogiar la vida y obra del jesuita y añadir información, ya que indica que

[...] el mismo amor que [Núñez] tenía a la Compañía, y su instituto, le hacía favorecerla quanto podía, valiéndose para su defensa, en muchos casos bien arduos y diffíciles, de la authoridad que tenía para con todos y de sus grandes letras. Y no menos procuraba ayudarla y fomentarla en lo temporal, zelando el acrecentamiento de la Provincia para gloria de Dios. Y a su diligencia, consejo y cuidado se fabricó de nuevo la iglesia del Collegio de S. Gregorio a expensas del capitán D. Juan de Echabarría, quien añadió demás del Collegio una hazienda de campo para que se sustentassen en el dicho Collegio algunos padres que atendiesen a la enseñanza de los indios mexicanos, y cuidassen de la buena crianza y educación de sus hijos, como oy se hace con tanta gloria de Dios, y utilidad de aquella miserable gente, y todo se debe a la direción [sic], cuidado y diligencia del padre Antonio. (Oviedo 1702, pp. 166-167).

Desde 1682, el padre Núñez contaba con una cantidad de dinero suministrada por el capitán para gastos. Se tiene noticia de que el 2 de septiembre del mismo año se expidió un recibo por 1.890 pesos a favor del padre Bernardo Pardo, provincial de la Compañía, con el fin de resolver un pleito sobre cobranzas (Zambrano 1970, t. 10, p. 528). Por último, el lunes 30 de noviembre del mismo año se dio sepultura al capitán Chavarría en la iglesia de San Lorenzo, como correspondía. No se dan más detalles de su deceso ${ }^{11}$, pero se incluye que se decía «deja 500.000 pesos» (Robles 1972, t. 2, p. 33).

$\mathrm{Y}$, en 1683, en su testamento,

legó para el sustento de los padres-lenguas del colegio de San Gregorio [...] la hacienda de S. José Oculmás (otras veces Acolman), que su albacea D. Nicolás de Vivero, conde del Valle de Orizaba, entregó a su co-albacea el padre

10 Ratifican esta información Castorena Ursúa y Sahagún de Arévalo: «En la iglesia de S. Gregorio, que (a influxo del R. P. Antonio Núñez de Miranda) se fabricó de los bienes del capitán D. Juan de Chavarría Valera, Cavallero del Orden de Santiago, y en donde se venera en su santa casa la milagrosíssima imagen de nuestra Señora de Loreto, se ha celebrado su novena con toda solemnidad» $(1986$, t. 1, p. 74). [En esta y las demás citas se respeta la ortografía, no así la acentuación ni puntuación. Asimismo, se desatan las abreviaturas].

1" Oviedo nos proporciona otro dato curioso referente al padre Núñez, a su vez en las postrimerías de su vida: «También parece que tuvo el padre Antonio algunas noticias de la otra vida por medio de almas que se le aparecieron. No mucho después de la muerte del capitán $\mathrm{D}$. Juan Echavarría [...], estaba el P. Antonio sentado en una pequeña sillita que tenía en su aposento, y sin advertir que estaba en él su compañero, le oyó éste decir estas palabras: $a$, buen D. Iuan: ocho días no más estuviste en el Purgatorio. Y lo hace esto muy creible la christiana generosidad y largueza con que este cavallero socorría en vida las necessidades de los pobres, pues tantas vezes promete Dios en las Escrituras, abiertas de par en par, las puertas del Cielo a los limosneros [...]». (Oviedo 1702, p. 199). 
Núñez para que esto lo hiciese al Colegio en 19 de febrero de 1683. (Zambrano 1970 , t. 10, p. 528).

Cabe preguntarse en qué consistía este donativo que había sido declarado y cedido por Nicolás de Vivero Peredo y Velasco, conde de Orizaba (además, vizconde de San Miguel, encomendero de Tecamachalco y hermano de Chavarría) ante notario, en $1681^{12}$. Se trataba de una extensa propiedad que incluía nada menos que la hacienda de San José de Acolman y su rancho de San Agustín, borregos, carneros, caballos, mulas, vacas, bueyes y novillos, amén de plantíos de trigo, maíz (AGN, Colegios, vol. 24, exp. 25, fols. 5v-10v), frijol y habas (AGN, Archivo Histórico de Hacienda, caja 286, exp. 33, sin foliar) y, claro está, los trabajadores y esclavos necesarios para encargarse de cosechas, trasquilas, etcétera y así mantener todo ello funcionando.

Por si esto fuera poco, el legado incluía la cobranza de unas deudas ${ }^{13}$. Así, el padre Núñez, al aceptar tan importante regalo, había adquirido la obligación de administrar todo aquello. ¡En menudo quebradero de cabeza se había metido don Antonio! Aguantó —con el estoicismo propio de su condición, suponemosdurante cuatro años. Dado lo anterior, no extrañará a nadie que enviara una carta de su puño y letra a su «amantíssimo hermano Bartholomé González» el 10 de noviembre de 1687, de la que extraemos algunos fragmentos:

Viendo que no son compatibles las temporalidades y su manejo con el de las cosas espirituales a que el Señor me ha dado aun más intensa aplicación, al presente, con deseo de lograr este poco tiempo de vida que me puede restar, compensando en Él algo de lo mucho perdido etcétera, rogué al padre provincial encargasse esta administración en el todo, así las dos haziendas, como las casas, al padre Pedro de Medina que en negocios algunos que a manejado muestra genio, inteligencia y actividad, muy a propósito y por eso yo también se lo rogué.

12 En ese mismo año, el capitán Chavarría había comprado la propiedad al también capitán Antonio de Medina, por un precio rebajado de 10,532 pesos y 2 tomines, ya que tenía problemas de uso de agua y de tierras con los indios, además de autos y multas de la Real Hacienda. El conde del Valle cedió la hacienda como herencia al padre Núñez: «dicha hacienda se havía de entregar a su paternidad para ciertos efectos que a su tiempo se manifestaría». (AGN, Colegios, vol. 24, exp. 25, fols. $1 \mathrm{r}-2 \mathrm{v}$ ).

13 En 1681 el capitán Chavarría cedió poderes a los padres Thomás Altamirano, Antonio Núñez, Daniel Ángelo Marras y Joseph Ossorio para cobrar algunas deudas a su favor. Resulta que desde 1679 Alonso Rascón y Sandoval le debía 34.867 pesos que cubría con unas propiedades en la provincia de Sonora. Su representante, el capitán Jacinto Muñoz de Moraza había entregado un cargamento de ropa, otros efectos y dinero al rector del colegio de Matepec con valor de 11.227 pesos, 4 tomines. Por esta cesión, los 34.867 pesos antes referidos quedaban a disposición del Colegio de San Gregorio, donde serían administrados por el padre Núñez, como albacea de Chavarría. (Cfr., AGN, Archivo Histórico de Hacienda, caja 286, exp. 22, fols. 1r-2r). 
Y su $[\ldots]^{14}$ como tan religioso la a admitido: y así va allá para que mi hermano le informe de los frutos que ay en [...] hazienda para que los pueda beneficiar, pagando, en primer lugar las deudas, reservando mil pesos o más para la tresquila y ver si el resto alcanza para quitar el censo ${ }^{15}$ de los 30 pesos de Ocolma, o lo que alcansare.

El año pasado de 86 , me escribió mi hermano, paraban allá más de 40 pesos de frutos. Respondí reservasse mi hermano mil pesos para la tresquila de 87 y los 30 se aplicassen a quitar dicho censo. Este año de 87 no sé los frutos que a habido, ni el resto de pagos de deudas. Yo no he percebido ni gastado nada de estos dos años [...]

Mi hermano, como quien es tan religioso, y no menos hombre de bien, [...]do fiel y ajustado, y por la charidad que me hace, se servirá de informar al [...] de todo y juntamente advertirle todo lo que jusgare conveniente para el buen logro de los frutos, que mi hermano a trabajado, y augmento de eso, hazienda que [...] está censionada y de mi parte aplicad[...] al Collegio de San Gregorio [...]

Por [...] intención del bienechor, es que [...] no admite la Compañía todos los frutos [se] gasten y empleen en augmento de las [dichas] haziendas y no el Collegio y [...] no el de su cargo, ni los frutos [...]. Así está enterado el padre Pedro de Medina, a quien ruego a mi hermano, por amor de Dios informe de todo lo que fuere conveniente para la conservación y augmento de una $[. .$.$] y$ otra hazienda, y le prevenga los malos o buenos pasos que al principio pueden sobrevenir, para que vaya sobre avizo [...] lo acierte. Y a mí me ocupe en lo que gustare, que siempre estaré para servirle y con mucho agradecimiento a lo que les a assistido.

El Señor se lo pague y que a mi hermano, y le dé la salud, esfuerso y buenos succesos que más conviene para el descanso de este Collegio, etcétera. México y noviembre 10 de 1687 . Siervo y hermano de mi charíssimo Antonio Núñez. (Biblioteca Nacional de Antropología e Historia, col. Colegio de San Gregorio, vol. 119, fols. 72r-73r).

Se comprende que el padre Núñez, con sesenta y nueve años a cuestas y problemas serios de vista (Oviedo 1702, passim) quisiera desligarse de tan difícil encargo. Por una parte, no podía manejar el producto de las propiedades a su antojo, pues «el bienechor» (Chavarría) había dejado claramente estipulado en qué se había de invertir y las haciendas, por lo que parece, no eran fáciles de llevar. Por la otra, además de tomar decisiones, administrar y llevar cuentas muy claras de todo, tenía que supervisar y estar en constante comunicación con los viceprocuradores de compras y asuntos legales, así como con el almacenista,

14 Los espacios en blanco se deben a la encuadernación muy apretada del volumen que impide la lectura.

15 Deudas a largo plazo. 
informar al procurador y, en su caso, al rector del Colegio de todos los asuntos relacionados con dichas fincas (cfr. Riley 1976, gráfica A, p. 25) ${ }^{16}$.

Sin embargo, y muy a su manera ${ }^{17}$, no da estas razones al pedir -suplicar, casi- que lo releven de tan pesada carga, sino que hábilmente disfraza la situación, aludiendo que se contrapone a sus tareas de asuntos espirituales: no quiere restarle más tiempo — ni mucho menos Ios años que le quedan - a Dios y a $\mathrm{Su}$ servicio, que, finalmente, es a lo que se ha dedicado muchos lustros, para lo que mejor sirve y donde puede ejercer su influencia sin cortapisas: evidentemente, las materias temporales son secundarias a las del espíritu; su talento y celo están desperdiciados. Así, propone un sucesor más joven, inteligente, de empuje, con alguna experiencia en tejemanejes hacendarios y al que ruega acepte, pues don Antonio, en realidad, no se ha ocupado de estas cuestiones en muchos meses y, sospechamos, está harto de ellas. Quizá pudiera haber otra explicación para su carta de renuncia pero, hasta el momento, nuestra investigación no ha arrojado tal información.

$$
* * *
$$

Cuatro largos y pesados años habían pasado desde que el padre Núñez predicara - el 1 de diciembre de 1683-- aquel elogioso sermón sobre el capitán Juan de Chavarría Valera (Núñez 1684, fols. 1r-36v), sin sospechar siquiera lo que le esperaba. En su prédica -en realidad son dos sermones complementariosvuelca toda su pasión léxica y agradecimiento al gran benefactor de la Compañía y de los pobres.

En la dedicatoria nos informa que conocía bien al capitán por haber sido su confesor, ofrece el sermón a su hermano, el conde del Valle y, no podía faltar, pide perdón de antemano por si «su mal historiado vosquejo» pudiera ofender: sus yerros si acaso se deberán a desconocimiento, no a falta de oficio del orador (pp. ii-iii $\left.^{18}\right)$.

16 Si bien el esquema de Riley se refiere al siglo XVIII, se llevaba un sistema de revisiones, supervisiones y cotejos muy parecido en el XVII.

17 En enero de 1668 llegó a manos del Santo Oficio un opúsculo intitulado Familiar prosopopeia. Epistola estimativa..., cuyo autor era «un sacerdote de la Congregación de la Puríssima». Fue censurado con rigor, se expidió un edicto para su prohibición y, después de una serie de averiguaciones, resultó ser del padre Núñez que, - suponemos-- preocupado, escribió una larga carta al Tribunal. En ella jamás hace mención de lo inconveniente - además de peligroso- de la situación, pues, dada su trayectoria de notoriedad e influencia, en menudo escándalo se habría visto envuelto de salir el asunto a la luz pública. Simple y llanamente hace una confesión revestida de humildad en la que pide que el texto sea censurado, pero no su persona; después de todo, el escrito - al menos oficialmente y a los ojos de los no enterados- era anónimo. (Cfr., Méndez 1997, pp. 400-405).

18 La numeración es mía, pues, como era costumbre, las hojas preliminares carecían de ella. Las citas que siguen se refieren al sermón, por lo que sólo se incluirán los folios. 
En la propositio introduce el gran tema envolvente a tratar: la heroica virtud y preciosas dádivas de Chavarría, «su religiosa charidad y liberalíssimas limosnas» (fol. 2r-2v). Califica su clasificación de temas de «acomodación panegýrica», proponiendo que un individuo que sea rico y justo es gran milagro y milagrosa santidad: bienaventurado es el rico que pasa sin pecado (fol. $3 \mathrm{r}-3 \mathrm{v}$ ). Hace mención, en la narratio, de su segundo gran tema: así como el árbol del Paraíso es el origen de todos los pecados, el oro y las riquezas son causa y cebo de la mortal avaricia, causa «universalíssima de su [la del hombre] eterna condenación» (fols. 4r-5r). Chavarría es un rico justo y caritativo, por tanto, merece ser beatificado y Núñez, ni tardo ni perezoso, así lo hace. Dos artículos capitales son necesarios para tal acontecimiento: virtudes aprobadas y bien probados milagros. Para Núñez, Chavarría los cumple con creces: es «el milagro de nuestro tiempo y prodigio deste Nuevo Mundo»; llegó a vivir entre sus abundancias sin mácula ni culpa por sus «heroicas virtudes y cuantiosas limosnas», pues

sobre la natural inclinación y consentido sentimiento de los hombres, y más contra su propenso abuso, no amó desordenadamente sus riquezas, ni se contaminó en culpa alguna por adquirirlas, conservarlas y aumentarlas, antes conservó siempre su conciencia sin mancha, entera e intacta. No amó desordenadamente sus riquezas más que a Dios [...]; quería antes perderlas que ofenderle [...] Supo amar no sólo a Dios por sí, sino al próximo también por Dios (fols. $5 \mathrm{r}-7 \mathrm{r}$ ).

En Chavarría se hizo un raro milagro cuando, siendo rico no pecó ya que, como todo lo podía («por eso los llama el Mundo poderosos»), en potencia, tenía más oportunidades de desviarse del buen camino que los pobres. Tal hecho

es una milagrosa aprobación de justo, es una authéntica información de perfecto, y una real executoria de consumado en toda virtud [...] porque pudo traspasar toda la ley de Dios y no la descantilló en una jota, ni en un ápice. Porque pudo obrar todo lo malo, no sólo sin dificultad, ni contradicción, pero aun con atractiva facilidad y gustoso aplauso de sus interezados aduladores y cómplices, y no lo hizo, ni quizo (fols. $7 \mathrm{v}-8 \mathrm{r}$ ).

Aunado a esta virtud milagrosa no tuvo que ver con mujeres, no vivía de los resplandores del dinero, no se dejaba adular: era un ejemplo de cristiana templanza, moderación y prudencia. Nunca hizo nada ilícito. Para Núñez estos eran muchos milagros juntos, comprobables. Hacían al capitán merecedor de la beatificación, por lo menos en la prédica (fol. 8v): «aclamémosle, pues, bienaventurado: Beatus dives» (fol. 10r), dice el jesuita en tono de arenga.

En la confirmatio menciona el testamento del capitán, para ratificar sus acciones virtuosas. El documento era

uno de los más cuantiosos que ha havido en las Indias, entre tantos centenares de miles y millares de millares que dispone, apenas se hallará o no se hallará aún apenas manda alguna, no digo profana, pero ni pura humana (fol. 11v). 
Corrobora y aprueba lo anterior al incluir que siempre consultaba el capitán con él cualquier duda y el jesuita llegó a admirarle y venerar a Dios en él, por su vista de lince para discernir lo mejor y constante justificación de sus acciones, aun a costa de sus intereses (fol. 12v).

En la peroratio resume lo anterior y recurre a una moraleja, aconsejando que con las riquezas se gane a los pobres por amigos, para que al acabar «la administración de esta temporal vida» se abran las puertas del Cielo para ellos y para los caritativos (fol. $15 \mathrm{r}-15 \mathrm{v}$ ).

No nos detendremos tanto en el segundo sermón para no alargar este trabajo. Baste decir que es una confirmación del anterior e incluye detalles sobre la erección de la iglesia de San Gregorio, costeada por Chavarría, para salvación y perfección tanto de los jesuitas que en ella radiquen como de los pobres, humildes y desechados naturales a los que enseñen. Se menciona que el caudal del capitán siempre está estable y aumenta porque gran parte de él lo usa para dar limosna a los pobres, a quienes reparte anónimamente dinero a manos llenas. Se vale de cuatro «limosneros» (entre los cuales están el capitán Juan Pérez Gallardo y el mismo padre Núñez) que llevan a cabo la piadosa labor por él, para no parecer vanidoso. También se describen otras obras que ha sufragado: la capilla de nuestra Señora de Guadalupe de la archicofradía del Santísimo Sacramento y sus ornamentos, la fundación del monasterio de San Lorenzo, sus retablos y altares, el oratorio de la Purísima y sus adornos, la propia iglesia de San Gregorio, su ayuda a varios conventos, hospitales, etcétera. Se insiste en que el dadivoso militar nunca esperó ni quiso agradecimiento alguno. Para terminar este cuadro que se podría antojar ficticio, apunta el padre Núñez, «y nadie piense ni sospeche que esta es más piadosa consideración mía, que hecho histórico suyo, porque no es sino verdad real de su religiosa piedad» (fol. 36r).

Administrador poco común hemos llamado al padre Núñez, sí, pero elocuente orador; ése sí que era su elemento, como connota su carta de 1687 y pone de manifiesto su sermón de 1683 . Se explaya, describe, excita e incita, y no pierde detalle para conmover a sus oyentes y premiar al sujeto de su elogio como, en su tiempo, sólo él sabe hacerlo. Su palabra era de peso y de pesos habló con maestría.

Hábil procurador de fondos para su amada Compañía que aprovechó el dictamen del inspector enviado por el General de Roma en aquel entonces lejano $1592^{19}$

19 El inspector informó que «invertir fondos en ranchos y granjas constituía el único método abierto a la provincia de la Nueva España para asegurarse un ingreso considerable y en aumento» (cfr. Riley 1976, p. 19). 
para conseguir más inversiones. Poseedor de gran visión hacia los intereses financieros jesuitas: la hacienda de Acolman estaba cercana a la de Santa Lucía que era propiedad del Colegio Máximo de San Pedro y San Pablo y en la misma región que Tepozotlán (Riley 1976, mapa 1, p. 20). Al igual que el celo, elevados principios y superioridad de su sistema educativo permitieron a la Compañía codearse con los poderosos (cfr., Chevalier 1963, p. 230), el padre Núñez consiguió su ayuda debido a su capacidad de convencimiento, prestigio, reputación e influencia en esta descrita, pero poco conocida faceta de su larga vida.

\section{BIBLIOGRAFÍA}

BERISTÁIN DE SOUZA, José Mariano. 1883. Biblioteca hispano americana septentrional, México, Fuente Cultural, t. 4.

BRAVO ARRIAGA, María Dolores. 1997. La excepción y la regla. Estudios sobre espiritualidad y cultura en la Nueva España, prefacio de José PASCUAL BUXÓ, México, Universidad Nacional Autónoma de México (Instituto de Investigaciones Bibliográficas y Facultad de Filosofía y Letras).

CASTORENA URSÚA Y GOYENECHE, Juan Ignacio María de y Juan Francisco SAHAGÚN DE ARÉVALO Y LADRÓN DE GUEVARA [1722-1742] 1986. Gacetas de México, reimp. de la ed. facsim., de México, advertencia de J. L. MUTIOZÁBAL, estudio introductorio de Francisco GONZÁLEZ DE COSSÍO, México, Centro de Estudios de Historia de México Condumex, $3 \mathrm{t}$.

CHEVALIER, François. 1963. Land and Society in Colonial Mexico, trad., Alvin EUSTIS, Berkeley, University of California Press.

DECORME, Gerard. 1941. La obra de los jesuitas mexicanos durante la época colonial 1572-1767, México, Antigua Librería Robredo de José Porrúa e Hijos, t. 1.

GERHARD, Peter [1972] 1986. Geografía histórica de la Nueva España 15191821, trad., Stella MASTRANGELO, mapas de Reginald PIGGOTT, México, Universidad Nacional Autónoma de México (Instituto de Investigaciones Históricas e Instituto de Geografía).

GUIJO, Gregorio M. de. 1986. Diario 1648-1664, ed. y prólogo de Manuel ROMERO DE TERREROS, México, Editorial Porrúa, t. 1.

MÉNDEZ, María Águeda. 1997. «No es lo mismo ser calificador que calificado: una adición a la bibliografía del padre Antonio Núñez, confesor de sor Juana», en Martha Elena VENIER (ed.), Varia lingüistica y literaria. 50 años del CELL. II. Literatura: de la Edad Media al siglo XVIII, México, El 
Colegio de México (Centro de Estudios Lingüísticos y Literarios), pp. 397413.

NÚÑEZ, Antonio. 1684. Oración funeral, sermón de honras a las que el muy ilustre señor conde del Valle, etc., como su principal testamentario y único heredero hizo al muy noble y piadoso caballero su hermano, el señor capitán Juan de Chavarría Valera..., México, Viuda de Bernardo Calderón.

OVIEDO, Juan Antonio de. 1702. Vida ejemplar, heroicas virtudes y apostólicos ministerios del V. P. Antonio Núnez de Miranda de la Compañía de Jesús..., México, Herederos de la viuda de Francisco Rodríguez Lupercio.

RILEY, James Denson. 1976. Hacendados jesuitas en México. La administración de los bienes inmuebles del Colegio Máximo de San Pedro y San Pablo de la ciudad de México, 1685-1767, México, Secretaría de Educación Pública.

ROBLES, Antonio de. 1972. Diario de sucesos notables (1665-1703), ed. y prólogo de Antonio CASTRO LEAL, México, Editorial Porrúa, 3. t.

TRABULSE, Elías. 1996. La memoria transfigurada. Tres imágenes históricas de Sor Juana, México, Universidad del Claustro de Sor Juana.

ZAMBRANO, Francisco, S. J., 1970. Diccionario bio-bibliográfico de la Compañía de Jesús en México, México, Editorial Jus, t. 10. 